\title{
SISTEM INFORMASI PEMESANAN JASA WEDDING ORGANIZER PADA YOUZHIE PENGANTEN DENGAN MENGGUNAKAN BAHASA PEMOGRAMAN PHP DAN MYSQL
}

\author{
Vicky Ariandi \\ Universitas Putra Indonesia YPTK Padang \\ Email : vicky tanjung@yahoo.com
}

\begin{abstract}
Web design Ordering Wedding Organizer Services at Youzhie Bride aims to make it easier for the public to obtain information on ordering wedding services (online) that were previously known from the mouth of the mouth so that they can save time, here I make it easier for people to order online so they can be efficient and effective. This final project can help in building an online ordering system. The design system in making websites Ordering Wedding Organizer Services at Youzhie The bride was developed using several software namely xampp, Notepad ++, Server which is a combination of Web Server, PHP and MySQL
\end{abstract}

Keywords: MySQL, PHP, Youzhie Bride

\section{PENDAHULUAN}

Wedding organizer adalah suatu jasa yang berfungsi secara pribadi membantu calon pengantin dan keluarga dalam perencanaan dan supervisi pelaksanaan rangkaian acara pesta pernikahan sesuai dengan jadwal dan budged yang telah di tetapkan. Wedding organizer sering kali di cari oleh masyarakat karena selain untuk mempermudah dalam melakukan perencanaan pesta pernikahan, wedding organizer juga sangat membantu bagi orang orang yang tidak mau repot dengan masalah perencanaan pernikahan mereka. Mulai dengan perkembangannya teknologi sekarang ini wedding organizer mulai berpindah dari proses manual ke dalam proses online yaitu dengan pembuatan wedding organizer berbasis web.

Wedding Organizer adalah salah satu usaha yang bergerak di bidang jasa khususnya pada acara pernikahan, pemesanan jasa wedding organizer pada Youzhie Penganten masih dilakukan dengan cara manual. Klien jasa wedding organizer pada Youzhie Penganten ini harus datang ke kantor langsung untuk melakukan pemesanan. Promosi wedding organizer masih dilakukan melalui orang ke orang dan melalui brosur yang berdampak masih rendahnya peminat jasa wedding organizer pada Youzhie Penganten dan diperlukan media promosi lain yang lebih baik dan dapat dilihat banyak orang.

Wedding Organizer mempunyai banyak pilihan model acara pernikahan yang disesuaikan berdasarkan jumlah undangan, keuangan, catering, gedung serta dekorasi pelaminan pengantin. 


\section{METODOLOGI}

Berdasarkan latar belakang yang telah diuraikan di atas maka dapat disimpulkan rumusan masalah pada penelitian yaitu:

1. Bagaimana membuat sistem promosi yang baik dan menarik untuk wedding organizer pada Youzhie Penganten?

2. Bagaimana perancangan sistem informasi pemesanan jasa wedding organizer berbasis web pada Youzhie Penganten ?

3. Bagaimana pemesanan jasa wedding berbasis web dibuat agar dapat meningkatkan daya saing pada Youzhie Penganten ?

Berdasarkan rumusan masalah di atas maka penulis dapat mengemukakan suatu hipotesa sebagai berikut :

1. Pemesanan jasa wedding berbasis web dapat mengimplementasi aplikasi yang dirancang dengan menggunakan bahasa pemograman PHP dan database MySQL dapat mempermudah pemilik pelaminan mempromosikan pelaminannya

2. Pemesanan jasa wedding berbasis web ini dapat meningkatkan keuntungan penjualan serta dapat meningkatkan daya saing pada Youzhie Penganten .

3. Manfaat adanya aplikasi online berbasis web pada jasa wedding Youzhie Penganten yang menggunakan bahasa pemrograman PHP dan database MYSQL akan menghemat waktu, tenaga, biaya dan mempermudah konsumen dalam mendapatkan informasi, serta pemesanan jasa wedding organizer itu sendiri menjadi lebih efektif dan efisien dibandingkan mendatangi kantor tersebut secara langsung.

Untuk mengarahkan penelitian sesuai spesifikasi yang ditentukan, maka diberikan batasan masalah sebagai berikut :

1. Pembuatan sistem informasi pemesanan jasa wedding organizer berbasis web ini di batasi hanya pada pembuatan profil perusahaan, pemesanan dan pembayaran wedding pada Youzhie Penganten.

2. Sistem yang akan dirancang hanya berbasis web.

3. Sistem ini hanya diterapkan pada wedding organizer Youzhie Penganten.

\subsection{Tujuan dan Manfaat Penelitian}

Berdasarkan identifikasi masalah maka tujuan dari penelitian ini adalah sebagai berikut :

1. Untuk membuat sebuah website yang dapat mempermudah pimpinan/pengelola Youzhie Penganten dalam mempromosikan pelaminannya.

2. Untuk membantu pimpinan/pengelola Youzhie Penganten untuk meningkatkan pemesanan dan daya saing dengan menerapkan sistem informasi pemesanan berbasis web.

3. Untuk memudahkan calon pelanggan atau untuk memesan jasa wedding organizer pada Youzhie Penganten sehingga tidak perlu langsung datang ke kantor dan menghemat waktu.

memperoleh suatu manfaat yaitu sebagai berikut :

Berdasarkan rumusan masalah dan tujuan yang telah dipaparkan sebelumnya, diharapkan memperoleh suatu manfaat yaitu sebagai berikut :

1. Penulis

Sebagai sarana untuk menambah pengetahuan di bidang pemrograman komputer dan sistem pengolahan data agar dapat diterapkan pada kehidupan sehari-hari.

2. Perusahaan 
Sebagai bahan pertimbangan untuk menerapkan pemesanan online pada masa yang akan datang.

3. Pelanggan

Penelitian ini dilakukan agar dapat bermanfaat unutk memudahkan pelanggan memperoleh informasi yang up to date mengenai pelaminan terbaru yang sudah menggunakan website yang dapat diakses kapan saja dan dimana saja.

\section{ANALISIS}

Dari hasil penelitian yang telah dilakukan baik dengan melakukan survey langsung ke Youzhie Penganten maupun tidak langsung, maka dapat diuraikan kerja sistem yang ada pada Youzhie Penganten. Dimana dalam pengolahan data inventory, Youzhie Penganten membutuhkan waktu yang lama dan kurang efisien karena masih belum optimalnya penggunaan komputerisasi dan analisa yang dilakukan secara manual.

\section{KESIMPULAN}

Berdasarkan identifikasi masalah maka tujuan dari penelitian ini adalah sebagai berikut :

1. Untuk membuat sebuah website yang dapat mempermudah pimpinan/pengelola Youzhie Penganten dalam mempromosikan pelaminannya.

2. Untuk membantu pimpinan/pengelola Youzhie Penganten untuk meningkatkan pemesanan dan daya saing dengan menerapkan sistem informasi pemesanan berbasis web.

3. Untuk memudahkan calon pelanggan atau untuk memesan jasa wedding organizer pada Youzhie Penganten sehingga tidak perlu langsung datang ke kantor dan menghemat waktu.

Berdasarkan rumusan masalah dan tujuan yang telah dipaparkan sebelumnya, diharapkan memperoleh suatu manfaat yaitu sebagai berikut :

1. Penulis

Sebagai sarana untuk menambah pengetahuan di bidang pemrograman komputer dan sistem pengolahan data agar dapat diterapkan pada kehidupan sehari-hari.

2. Perusahaan

Sebagai bahan pertimbangan untuk menerapkan pemesanan onlinepada masa yang akan datang.

3. Pelanggan

Penelitian ini dilakukan agar dapat bermanfaat untuk memudahkan pelanggan memperoleh informasi yang up to date mengenai pelaminan terbaru yang sudah menggunakan website yang dapat diakses kapan saja dan dimana saja.

\section{Pengujian Program}

Pada bagian pengujian program ini akan dijelaskan mengenai penggunaan dari aplikasi yang dibuat. Penjelasan aplikasi yang dibuat meliputi tampilan aplikasi, fungsi kontrol dalam aplikasi, serta cara penggunaanya. Pada sub bab akan dijelaskan tentang penggunaan aplikasi per sistem menu, mulai dari tampilan menu utama, fungsi dan cara penggunaannya sampai selesai.

\section{Tampilan Form Login}

Pada tampilan login Youzhie Penganten terdapat tiga form yaitu akses (level Login ), e-mail dan 
password. pada form akses terdapat tiga level yaitu :

\section{Level Member}

Pada level member terdapat beberapa form yaitu :

1. Sign Up

Sebelum mengakses website pada Youzhie Penganten, member harus Sign Up dan mengisi datadata pribadi seperti Gambar 4.25.

2. Login Member
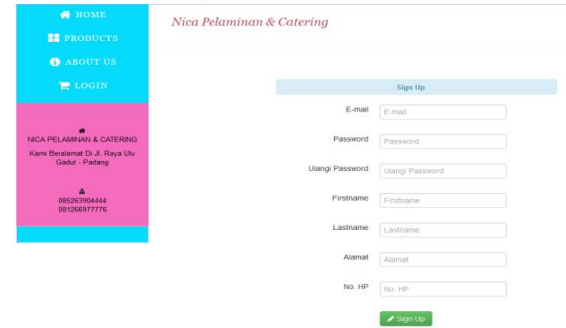

Gambar 5.1 Tampilan Sign Up

Setelah mengisi data-data pribadi, member harus login dengan menggunakan data-data yang telah di isi seperti Gambar 4.26.

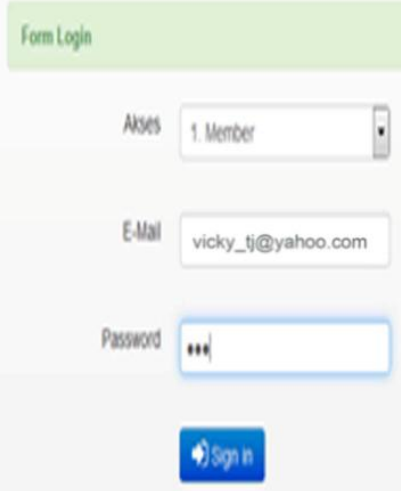

\section{Gambar 5.2 Tampilan Login Member}

3. Form Barang dan Jasa

Pada form barang dan jasa, member bisa melihat barang - barang dan jasa pada Youzhie Penganten seperti pelaminan, catering, tenda dan lainnya, seperti Gambar 4.27.

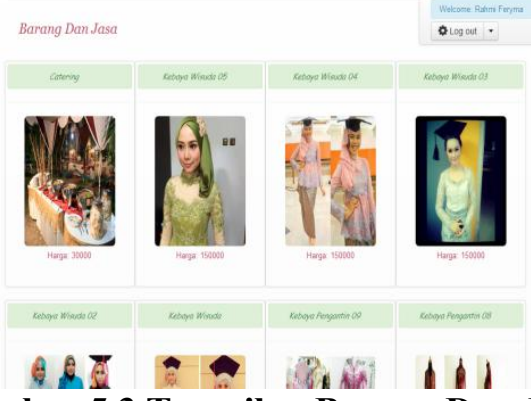

\section{Gambar 5.3 Tampilan Barang Dan Jasa}

4. Form Pemesanan

Pada form pemesan member mengisi data-data pemesanan seperti Gambar 4.28. 


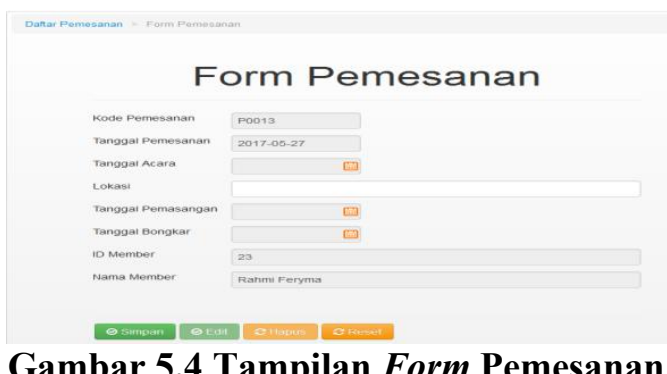

5. Form Detail Pemesanan

Gambar 5.4 Tampilan Form Pemesanan

Pada form detail pemesanan member memilih barang-barang dan jasa apa saja yang akan di pesan seperti Gambar 4.29.

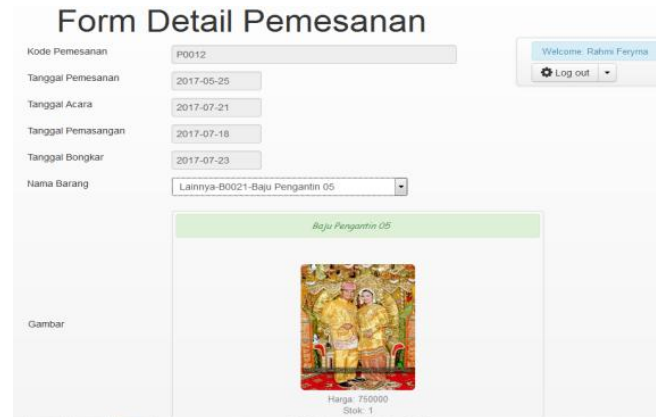

\section{Gambar 5.5 Tampilan Form Detail Pemesanan}

6. Faktur Pemesanan

Setelah memesan beberapa barang pada Youzhie Penganten, member melihat dan mencetak faktur pemesanan, Member dapat melihat total dari keselurahan pemesanan seperti Gambar 4.30.

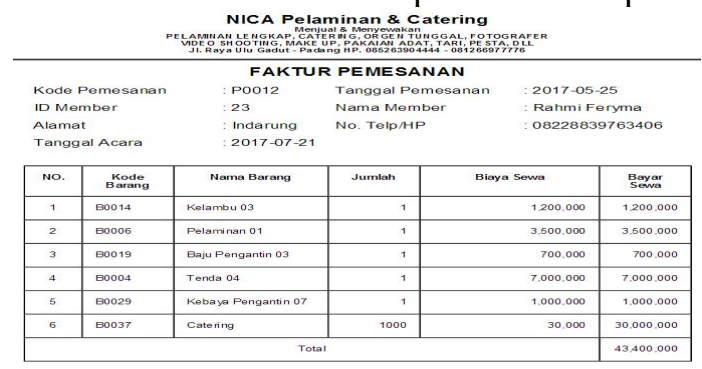

Gambar 5.6 Tampilan Faktur Pemesanan

7. Validasi pembayaran DP

Setelah melihat dan mencetak faktur pemesanan member harus membayar DP minimal 10\% dan mengisi form validasi pembayaran seperti Gambar 4.31.

Validasi Pembayaran DP

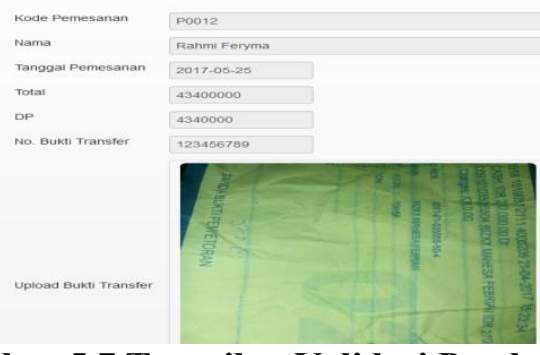

Gambar 5.7 Tampilan Validasi Pembayaran DP

8. Validasi Pelunasan 
Berikutnya member harus membayar pelunasan dari sisa total pemesanan, dan mengisi form validasi seperti Gambar 4.32.

Validasi Pelunasan

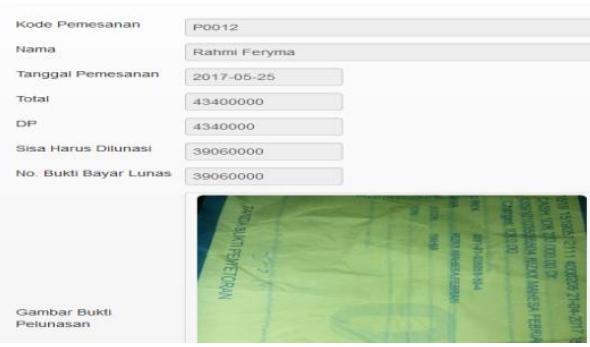

Gambar 5.8 Tampilan Validasi Pelunasan

9. Faktur Pelunasan

Setelah validasi pelunasan member melihat dan mencetak faktur pelunasan seperti Gambar 4.33.

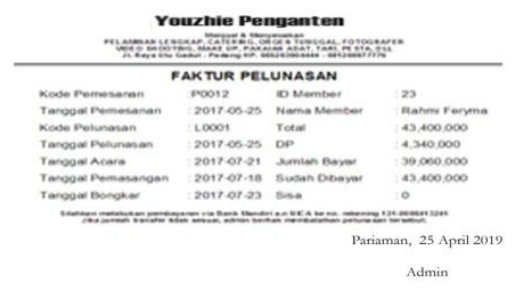

10. Logout

\section{Gambar 5.9 Tampilan Faktur Pelunasan}

Setelah mengakses dan memesan barang-barang, maka selanjutnya member logout.

\section{Level Admin}

Pada level admin terdapat beberapa form yaitu :

1. Login Admin

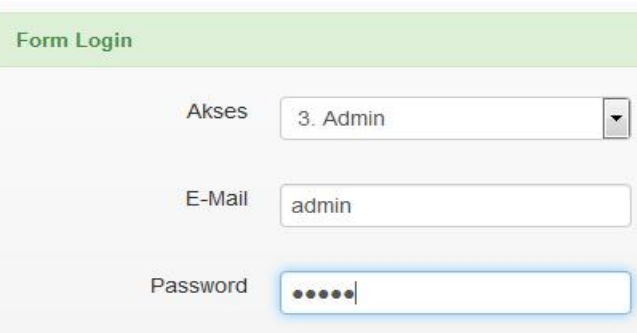

$\rightarrow$ sign in

2. Kelola Barang dan Jasa

\section{Gambar 5.10 Tampilan Login Admin}

Pada form barang dan jasa terdapat daftar barang-barang dan jasa yang ada pada Youzhie Penganten. Admin dapat mengelola data barang-barang pada Youzhie Penganten tersebut seperti Gambar 4.35.

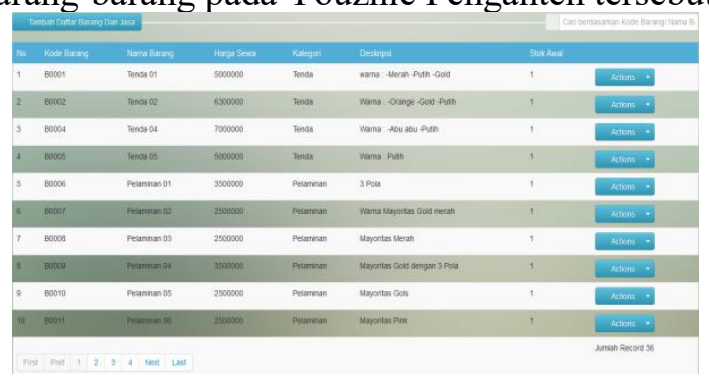


3. Form Data Member

\section{Gambar 5.11 Tampilan Kelola Data Barang Dan Jasa}

Pada form ini terdapat data-data member yang ada pada Youzhie Penganten seperti Gambar 4.36.

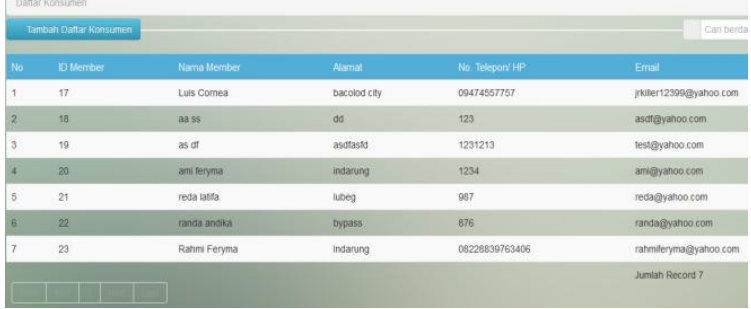

Gambar 5.12 Tampilan Data Member

4. Kelola Pemesanan Pada Admin

Pada form pemesanan pada admin terdapat data-data pemesanan member seperti Gambar 4.37.

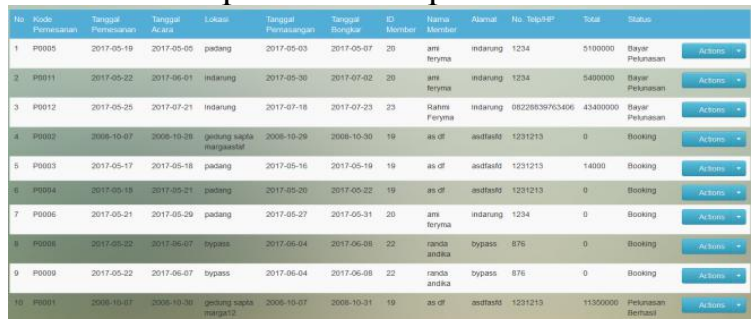

Gambar 5.13 Tampilan Data Pemesanan Member

5. Form Detail Pemesanan

Pada form detail pemesanan pada admin terdapat detail-detail barang yang telah di pesan oleh member seperti Gambar 4.38 .

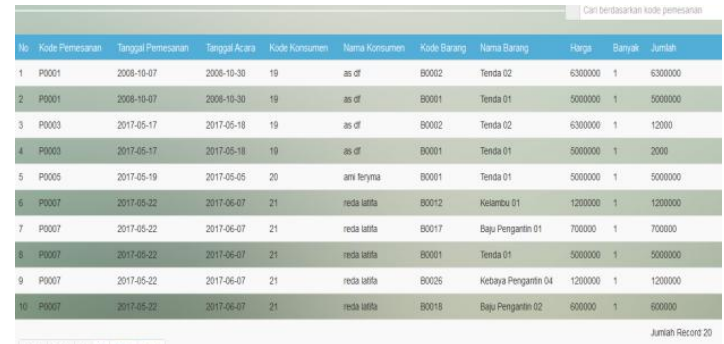

\section{Gambar 5.14 Tampilan Data Detail Pemesanan}

6. Form Kelola Pembayaran DP

Pada form kelola pembayaran DP admin dapat mengelola pembayaran DP member. Admin berhak menggagalkan pembayaran DP apabila member tidak membayar 2X24 jam seperti Gambar 4.39.

7. Form Kelola Pelunasan

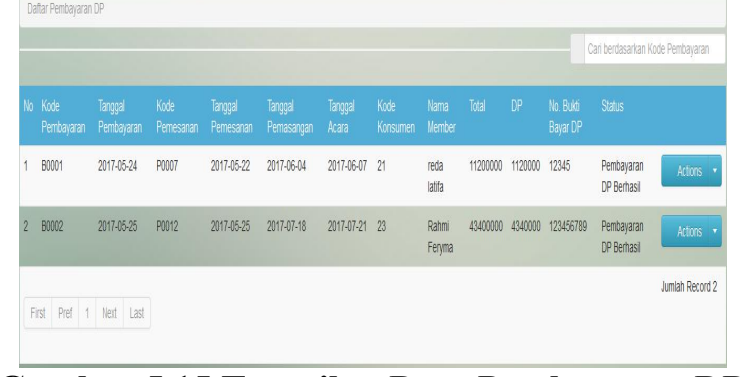

\section{Gambar 5.15 Tampilan Data Pembayaran DP}

Pada form kelola pelunasan ini admin dapat mengelola pelunasan member seperti Gambar 4.40. 
8. Laporan Data Barang

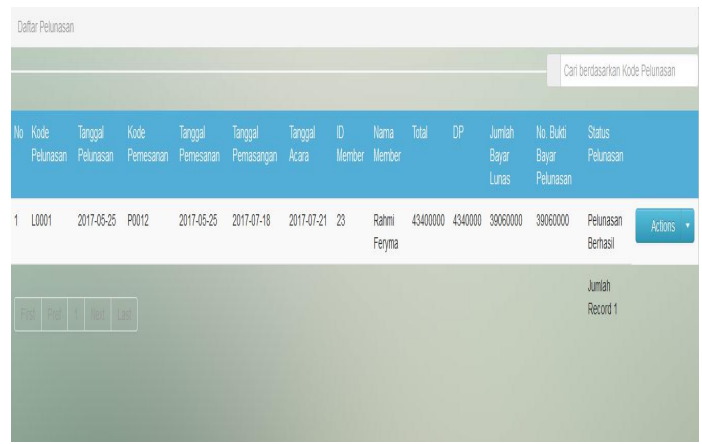

Gambar 5.16 Tampilan List Pelunasan

Laporan data barang dan jasa merupakan laporan yang berisikan tentang data-data barang dan jasa pada Youzhie Penganten seperti Gambar 4.41.

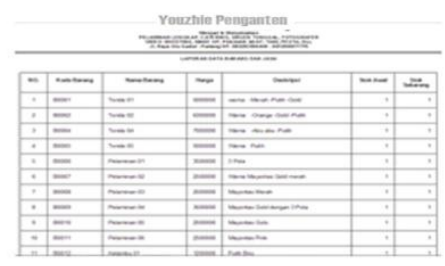

9. Laporan Data Member

\section{Gambar 5.17 Tampilan Laporan Data Barang Dan Jasa}

Laporan data member merupakan laporan yang berisikan tentang data-data member pada Youzhie Penganten seperti Gambar 4.42.

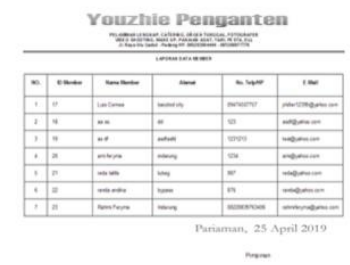

\section{Gambar 5.18 Tampilan Laporan Data Member}

10. Laporan Data Pemesana Per Tanggal

Laporan data pemesanan per tanggal merupakan laporan yang berisikan tentang data-data pemesanan Jasa Wedding Organizer pada Youzhie Penganten berdasarkan tanggal acara seperti Gambar 4.43 . 


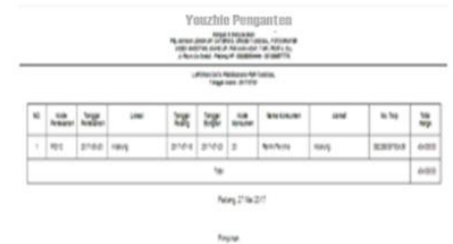

11. Laporan Data Pemesanan Per Bulan

\section{Gambar 5.19 Tampilan Laporan Data Pemesana Pertanggal}

Laporan data pemesanan per bulan merupakan laporan yang berisikan tentang rekapan data-data pemesanan Jasa Wedding Organizer pada Youzhie Penganten berdasarkan bulan acara seperti Gambar 4.44 .

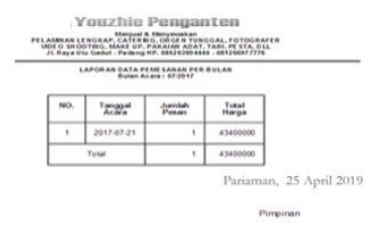

\section{Gambar 5.20 Tampilan Laporan Data Pemesana Per Bulan}

12. Laporan Data Pemesanan Per Tahun

Laporan data pemesanan per tahun merupakan laporan yang berisikan tentang rekapan data-data pemesanan Jasa Wedding Organizer pada Youzhie Penganten berdasarkan tahun acara seperti Gambar 4.45 .

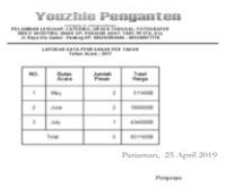

\section{Gambar 5.21 Tampilan Laporan Data Pemesana Pertahun}

13. Laporan pembayaran DP Per Tanggal

Laporan data pembayaran DP per tanggal merupakan laporan yang berisikan tentang rekapan datadata pembayaran DP Jasa Wedding Organizer pada Youzhie Penganten yang dilakukan oleh member berdasarkan tanggal pada tanggal pembayaran DP seperti Gambar 4.47. 


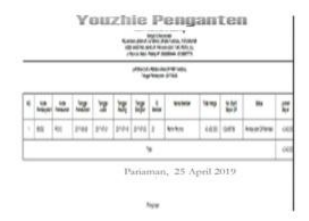

14. Laporan Pembayaran DP Per Bulan

Gambar 5.22 Tampilan Laporan Pembayar DP Per Tanggal

Laporan data pembayaran DP per bulan merupakan laporan yang berisikan tentang rekapan datadata pembayaran DP Jasa Wedding Organizer pada Youzhie Penganten yang dilakukan oleh member berdasarkan bulan pada tanggal pembayaran DP seperti Gambar 4.48.

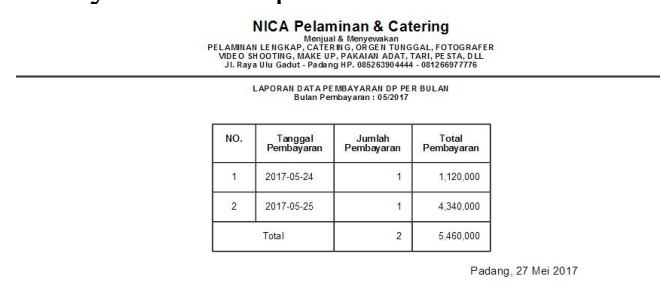

Gambar 5.23 Tampilan Laporan Pembayar DP Per Bulan

15. Laporan Pembayaran DP Per Tahun

Laporan data pembayaran DP per tahun merupakan laporan yang berisikan tentang rekapan datadata pembayaran DPJasa Wedding Organizer pada Youzhie Penganten yang dilakukan oleh member berdasarkan tahun pada tanggal pembayaran DPseperti Gambar 4.49.

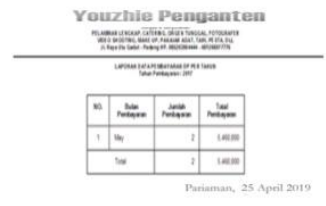

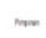

16. Laporan Data Pembayaran Per Pemesanan

Gambar 5.24 Tampilan Laporan Pembayar DP Per Tahun

Laporan data pembayaran per pemesanan merupakan laporan yang berisikan tentang rekapan datadata pembayaran Jasa Wedding Organizer pada Youzhie Penganten yang dilakukan oleh member berdasarkan kode pemesanan yang sudah ada transaksi pembayaran seperti Gambar 4.50. 


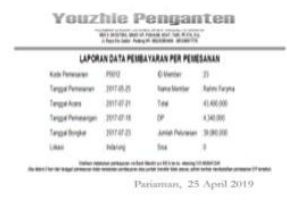

.

\section{Gambar 5.25 Tampilan Laporan Data Pembayaran Per Pemesanan}

\section{Laporan Pelunasan Per Tanggal}

Laporan data pelunasan pembayaran per tanggal merupakan laporan yang berisikan tentang rekapan data-data pelunasan pembayaran Jasa Wedding Organizer pada Youzhie Penganten yang dilakukan oleh member berdasarkan tanggal pada tanggal pelunasan seperti Gambar 4.51.

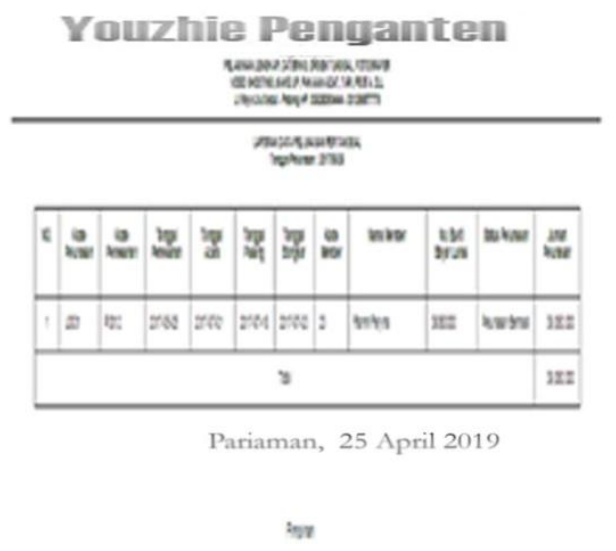

\section{Gambar 5.26 Tampilan Laporanan Pelunasan Per Tanggal}

18. Laporan Data Pelunasan Per Bulan

Laporan data pelunasan per bulan merupakan laporan yang berisikan tentang rekapan data-data pelunasan Jasa Wedding Organizer pada Youzhie Penganten yang dilakukan oleh member berdasarkan bulan pada tanggal pelunasan seperti Gambar 4.52.

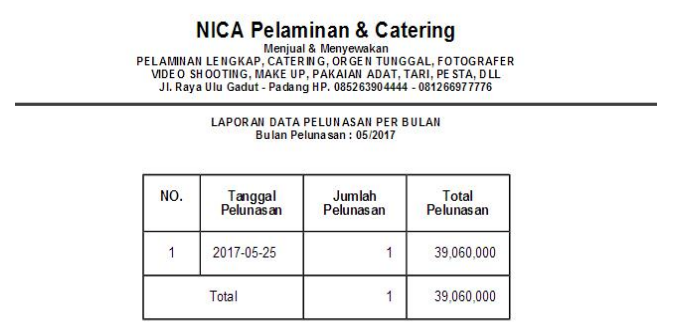

Padang, 27 Mei 2017

Pimpinan

Gambar 5.27 Tampilan Laporan Data Pelunasan Per Bulan

19. Laporan Data Pelunasan Per Tahun

Laporan data pelunasan per tahun merupakan laporan yang berisikan tentang rekapan data-data pelunasan jasa Wedding Organizer pada Youzhie Penganten yang dilakukan oleh member berdasarkan tahun pada tanggal pelunasan seperti Gambar 4.53. 


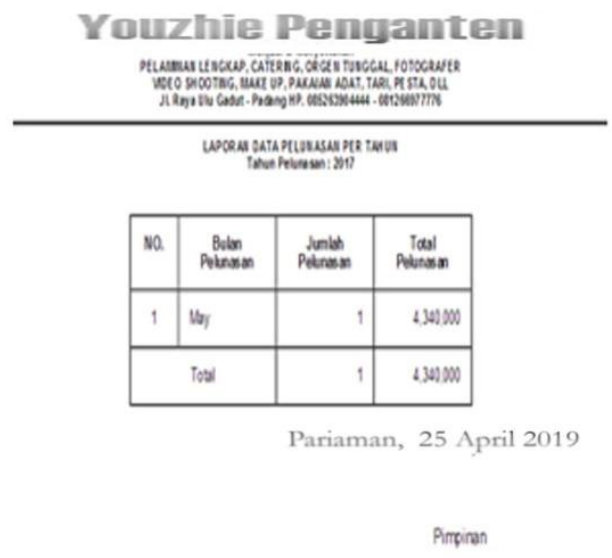

Gambar 5.28 Tampilan Laporan Data Pelunasan Per Tahun

\subsubsection{Level Pimpinan}

Ketika pimpinan ingin mengakses website, pimpinan harus login terlebih dahulu dan mengisi $E$ Mail dan Password. Pada level ini pipminan hanya bisa melihat laporan-laporan saja. Login level pimpinan dapat dilihat seperti Gambar 4.55.

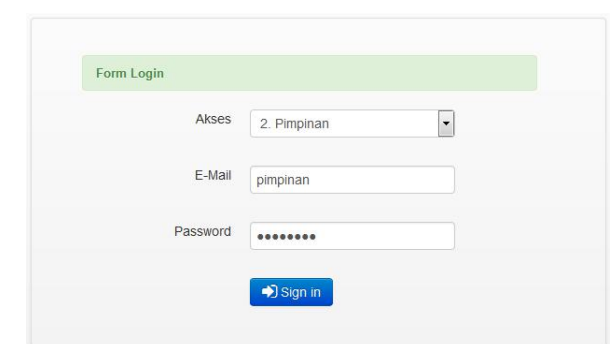

Gambar 5.29 Tampilan Login Pimpinan

\subsection{Kesimpulan}

Berdasarkan hasil pengamatan dan analisa perancangan sistem yang telah dilakukan Youzhie Penganten maka dapat diambil beberapa kesimpulan yaitu:

1. Aplikasi Pemesanan Jasa Wedding Organizer berbasis web pada Youzhie Penganten ini dapat mempermudah user mencari dan mendapatkan informasi yang dibutuhkan tentang Jasa Wedding realtime dan online.

2. Aplikasi Pemesanan Jasa Wedding Organizer berbasis web ini dapat meningkatkan volume transaksi sehingga menambah pendapatan Youzhie Penganten dan mempermudah transaksi pemesanan.

3. Aplikasi Pemesanan Jasa Wedding Organizer web ini dapat memudahkan Youzhie Penganten dalam mempromosikan produk pelaminannya secara bebas tanpa mengeluarkan biaya yang besar.

\subsection{Saran-saran}

Berdasarkan kesimpulan yang telah diuraikan sebelumnya, maka dapat dikemukakan beberapa saran yang diharapkan menjadi bahan pertimbangan dengan harapan agar berguna bagi yang menggunakan sistem ini :

Adapun saran-saran tersebut adalah sebagai berikut:

1. Terapkan sistem komputerisasi yang lebih optimal dengan menggunakan aplikasi agar lebih efisien dan efektif.

2. Bangun kerja sama dalam meningkatkan efisiensi kerja agar dapat mencapai tujuan. 
3. Setelah sistem ini dapat dioperasikan dengan maksimal maka bisa dijalankan untuk kepentingan Jasa Wedding Organizer Pada Youzhie Penganten.

\section{DAFTAR PUSTAKA}

A.S, Rosa, Shalahuddin, M. 2013.Rekayasa Perangkat Lunak. Bandung: Informatika bandung. Hasanah, Uswatun. 2013. SISTEM INFORMASI PENJUALAN ON_LINE PADA TOKO KREATIF SUNCOM PACITAN. Jurnal Emba

Kadir, Abdul. 2013. Pengenalan Sistem Informasi. Yogyakarta :Andi

Mandala, Eka Praja Wiyata, 2015. Web Programming Project 1 “e.p.w.m Forum”. Yogyakarta : Andi. Nugrahanti, Fatim (2015). Perancangan Sistem Informasi Inventory Sparepart mesinfotocopy dengan menggunakan visual delphi 7(Studi Kasus di UD. Eka Taruna Madiun).Vol.2 No.2 Jurnal Emba.

Muhammad Yogi Saputra, Sistem Informasi Pelayanan Paket Pernikahan Pada Nirwana Organizer Bekasi, Desember 2016, yogisaputra53@yahoo.com, volume 03, No. 2, ISSN : 2527-9777.

Pratama, I Putu Agus Eka, 2014.Sistem Informasi dan Implementasinya.Bandung :Informatika Bandung Raharjo, Budi. 2011. Belajar Otodidak Membuat Database Menggunakan MySQL.Bandung : Informatika Bandung

Saputra, Ade. 2015. Rancang bangun sistem pendukung keputusan penentuan keluarga miskin. Jurnal Emba

Tata Sutabri. 2012. Analisis Sistem Informasi. Yogyakarta: Andi

Tohari, Hamim. 2013. Analisis Serta Perancangan Sistem Informasi Melalui Pendekatan UML. Yogyakarta 
Majalah IImiah UPIYPTK, Vol. 26, No 1. Hal 52-64

ISSN : $1412-5854$, E ISSN : 2502-8774

copyright@2019 LPPM UPI YPTK 